\title{
Research Note: Effect of Simulated Shipping Temperatures on the Sensory Composition of South African Chenin Blanc and Sauvignon Blanc Wines
}

\author{
W.J. du Toit*, C. Piquet \\ Department of Viticulture and Enology, Private Bag X1, 7620 Matieland (Stellenbosch), South Africa
}

Submitted for publication: March 2014

Accepted for publication: June 2014

Key words: White wine, high temperatures, bottle ageing

\begin{abstract}
This work investigated the effect of constant and simulated shipping temperatures on the sensory composition of Chenin blanc and Sauvignon blanc wines. Wines exposed to elevated temperatures during the trial developed unwanted aromas, such as over-aged, sulphur-like and a yellow colour, while those left at a cooler temperature retained tropical aromas. However, varying temperatures did not lead to large aroma differences in wines compared to those left at a constant lower temperature. It thus seems that average temperatures play a larger role in the development of unwanted over-aged aromas in certain South African white wines than temperature variations.
\end{abstract}

\section{INTRODUCTION}

Sauvignon blanc and Chenin blanc are two important white wine varieties in South Africa. Wines made from these cultivars are often described as having fruity, guava and passion fruit aromas, which are partly due to volatile thiols such as 4-mercapto-4-methylpentan-2-one (4MMP), 3-mercaptohexan-1-ol (3MH) and 3-mercaptohexyl acetate (3MHA) (Coetzee \& Du Toit, 2012). However, some South African white wines have premature ageing aromas after a period of bottle ageing. It is known that elevated storage temperatures $\left(30^{\circ} \mathrm{C}\right)$ after bottling can have adverse effects on the aroma and general quality of wine (Marais \& Pool, 1980). The effect of varying storage temperature on white wine's aroma is not well known, especially during shipping. Robinson et al. (2010) found that elevated bottle storage temperatures led to significant changes in the sensory and chemical composition of both white and red wines. Different studies (Meyer, 2002; Rodriguez-Bermejo et al., 2007) have found that wine can be exposed to large variations in temperatures during transport and that these temperatures easily reach $40^{\circ} \mathrm{C}$ in shipping containers. The effect of such large variations in temperature on white wines is not well known. This is especially relevant for South Africa wine producers, who need to ship their export wines to European and other markets over large distances. Wine producers often state colloquially that temperature fluctuations are detrimental to wine quality during bottle ageing, although this has not been proven conclusively. The main aim of this work thus was to investigate the effect of different temperatures, as well as variations in temperature, on the sensory characteristics of South African Chenin blanc and Sauvignon blanc wines during a period that simulated the transport by ship from South Africa to Europe.

\section{MATERIALS AND METHODS}

Wines and temperature regimes used

Wines were stored at variable temperatures over a period of 46 days to simulate a typical export journey from dockyard (South African) to Europe (Meyer, 2002). We thus used the study of Meyer (2002) as a guide to design the experimental outlay of this trial. A commercial 2009 Sauvignon blanc (closed under cork) and a 2010 Chenin blanc (closed under screw cap) were used in these trials. These wines were obtained directly from the producing cellar and were prepared according to standard commercial winemaking procedures. Both wines were stored at constant temperatures $\left(-4^{\circ} \mathrm{C}, 15^{\circ} \mathrm{C}\right.$ and $\left.37^{\circ} \mathrm{C}\right)$, as well as at variable temperatures, for the 46-day trial period. The four wine treatments thus were a constant $-4^{\circ} \mathrm{C}$ (treatment 1$)$, variable (treatment 2$)$, a constant $15^{\circ} \mathrm{C}$ (treatment 3 ) and a constant $37^{\circ} \mathrm{C}$ (treatment 4) for 46 days. The variable temperatures were supposed to simulate a summer in South Africa and a winter in the northern hemisphere, with the wines being exposed to one week of variable high temperatures in the beginning and one week of variable low temperatures at the end of the trial. In the variable temperature treatments the wine were thus left at $30^{\circ} \mathrm{C}$ for eight hours per day, then moved to $37^{\circ} \mathrm{C}$ for eight hours and finally to $20^{\circ} \mathrm{C}$ for eight hours per day

\footnotetext{
*Corresponding author: wdutoit@sun.ac.za

Acknowledgements: The authors would like to thank Winetech, Thrip and the NRF for financial support, as well as Boschendal Estate and Distell, who donated wine for this experiment
} 
for the first week, which was supposed to simulate morning, afternoon and night-time temperatures in the dockyard in summer. This was followed by a period of 30 days' storage at a constant $15^{\circ} \mathrm{C}$, which was supposed to simulate the period of transport at a relative constant temperature on a ship, as indicated by Meyer (2002). The wines were then finally exposed to $-4^{\circ} \mathrm{C}, 4^{\circ} \mathrm{C}$ and $8^{\circ} \mathrm{C}$ for eight hours per day for the last week of the trial, which was supposed to simulate night, morning and afternoon temperatures in a dockyard in winter time. However, the average temperature over the 46day trial period was similar between those wines exposed to a constant $15^{\circ} \mathrm{C}$ (treatment 3 ) and to variable temperatures (average of $15.3^{\circ} \mathrm{C}$, treatment 2).

After this first trail with four treatments, we also exposed additional bottles of the 2010 Chenin blanc wine to $37^{\circ} \mathrm{C}$ and $15^{\circ} \mathrm{C}$ for seven and 14 weeks for a triangle tasting.

\section{Descriptive sensory analysis}

After the 46-day trial period, the wines were subjected to sensory evaluation. Descriptive sensory analysis (DSA) was used as a research tool for analysing the full spectrum of sensory attributes associated with the respective wines (Lawless \& Heymann, 2010). The DSA analyses were conducted at the Department of Food Science, Stellenbosch University. Judges with experience in wine analysis were chosen for their ability to assess aroma, flavour and certain mouthfeel descriptors, as well as for their descriptive language skills. All of the panellists had prior experience of wine assessment, i.e. the profiling of Sauvignon blanc for different levels of diacetyl, and red wines for cork and Brettanomyces taints. The panel consisted of nine women, ranging in age from 24 to 60 (Lawless \& Heymann, 2010).

Prior to performing DSA, the panel of judges was trained extensively in the orthonasal analysis of Sauvignon blanc and Chenin blanc wines (Lawless \& Heymann, 2010). In order to achieve this, the wine aroma wheel of Noble et al. (1987) was used as a starting point. This wheel divides aroma descriptors into primary and secondary descriptors. Judges were firstly encouraged to recognise the primary, more general, aroma attributes and then to move on to the secondary, more specific, aroma attributes generally associated with these two wines (Biasoto et al., 2010).

During the training phase of DSA, the panel was trained in ten consecutive sessions of approximately $1.5 \mathrm{~h}$ per session. During each training session, the panellists were exposed to the four wine treatments within the Chenin blanc experiment, as well as within the Sauvignon blanc experiment. Descriptors were generated for the respective wine treatments and discussed by the panel members until consensus was reached on the range of sensory attributes necessary to profile the respective wines, as well as on the minimum and maximum intensity value of each attribute. The attributes identified included the visual yellow colour of the wine, the aromas "fruity", "tropical", "sulphurlike", "over-aged" and, lastly, a "burning" sensation in the aftertaste of the Chenin blanc. The same attributes were used for the Sauvignon blanc, but "vegetative" aroma was also included (this referred to a green vegetative character often associated with Sauvignon blanc). During DSA training, the panel was also introduced to a range of reference standards illustrating the aroma attributes that could develop in wines when exposed to variable temperatures during shipping. For this, a range of Chenin blanc and Sauvignon blanc wines were sourced to illustrate the following aroma attributes: "fruity" (overall fruity character), "tropical" (including guava, pineapple, passion fruit character), "vegetative" (asparagus, green pepper character), "over-aged" (strong honey-like notes) and "sulphur-like" (wine with high levels of sulphur).

During the testing phase of DSA, the samples were analysed for the respective attributes on unstructured line scales anchored as follows: $0=$ No intensity and $100=$ Prominent intensity. The analysis was conducted in tasting booths equipped with Compusense five ${ }^{\circledR}$ software (version 5, Compusense, Guelph, Canada) and artificial daylight lighting. The room temperature was controlled at $20^{\circ} \mathrm{C} \pm$ $1^{\circ} \mathrm{C}$. The wines were analysed in standard ISO wine-tasting glasses at $20^{\circ} \mathrm{C} \pm 1^{\circ} \mathrm{C}$, and the sample size was $20 \mathrm{~mL}$. Each sample was coded with a three-digit blinding code and the judges received the full sample set in a completely randomised order according to a complete block design. Each glass was covered by a lid (Kimix, South Africa) and, prior to the aroma analysis, the judges were instructed to remove the lid from the glass, swirl the wine and analyse the specific aroma concentrated in the headspace area. After all aroma attributes had been analysed, the panel members were instructed to analyse the taste and appearance attributes. The analysis was replicated in six identical sessions on three consecutive days, with two replications per day. Six bottles of wine from each treatment were thus analysed. The descriptive analysis of the Chenin blanc samples was completed before moving on to the analysis of the Sauvignon blanc wine samples.

\section{Triangle tests}

Triangle tests were also conducted under the same conditions as described above. A panel of eight expert judges (all postgraduate students and staff of the Department of Viticulture and Oenology, Stellenbosch University) conducted these tests, in which the treatments exposed to $15^{\circ} \mathrm{C}$ were compared to those stored at $37^{\circ} \mathrm{C}$. Wine samples from each temperature treatment were drawn after seven and 14 days and tasted immediately. Triangle tests were conducted on four repeats of the treated wines, yielding 32 responses per storage time.

\section{Statistical analysis of data}

The DSA data were subjected to analysis of variance (ANOVA) using $\mathrm{SAS}^{\circledR}$ version 9.2 (SAS Institute, Cary, NC, USA). The Shapiro-Wilk test was used to test for nonnormality of the residuals. In the event of significant nonnormality ( $\mathrm{p} \leq 0.05$ ), outliers were identified and residuals larger than 3 were removed. Student's t least significant difference (LSD) was calculated at the 5\% level to compare treatment means. Principal component analysis (PCA) using the correlation matrix and partial least squares regression were conducted using XLStat (Version 7.5.2, Addinsoft, New York, USA) to visualise and elucidate the relationships between the samples and their attributes (Næs et al., 2010). Roessler tables (Jackson, 2007) were used to determine the minimum number of correct judgments needed to be deemed 
significant at the probability level of $\mathrm{p}=0.05$ in the triangle tests.

\section{RESULTS AND DISCUSSION}

Figure 1 shows the sensory data of the different Chenin blanc wine treatments. It is clear that treatment 4 differed from the other three treatments, with F1 explaining most of the variability between the samples $(96 \%)$. Treatment 4 thus was associated with negative characteristics, such as overaged, sulphur like and yellow colour, while the other three treatments were associated with tropical and fruity aromas. These differences were significantly higher in treatment 4 compared to the other three treatments (results not shown). These results correlate with observations by Francis et al. (1994) and Marais and Pool (1980), who also found decreases in fruity and floral characteristics of white wine exposed to increased temperatures $\left(45\right.$ and $30^{\circ} \mathrm{C}$ respectively). The compounds responsible for the over-aged character in white wines are not completely clear at this stage, but increases in vitispirane, 1,1,6-trimethyl-1,2-dihydronaphtalene (TDN), reminiscent of diesel (Robinson et al., 2010; Hopfer et al., 2012), and sotolon and 2-phenylacetaldehyde, with curry and honey-like aromas respectively (Coetzee, 2014) could explain the over-aged aroma character described by the panel. One-way ANOVA results of the sensory data of treatments 1, 2 and 3 did not show any significant differences between these treatments in terms of the sensory characteristics (results not shown). This indicates that variable temperatures did not influence the sensory composition of the Chenin blanc wine in this case, which has not been proven before in South African wines.

In Fig. 2, the sensory data of the Sauvignon blanc wine can be observed. Treatment 4 differed from the other three in F1, which explained $96 \%$ of the variance. Similar to the Chenin blanc wine, treatment 4 was described by significant increases in negatively associated characteristics, such as over-aged aroma and flavour, a burning sensation, yellow colour and sulphur aroma, while the other three treatments were associated with more positive notes, such as vegetative, fruity and tropical aromas. The sulphur-containing compound methional is formed under higher temperatures and oxidative conditions (Silva Ferreira et al., 2003) and, although not measured in this study, could have contributed to the sulphurlike aroma experienced by the panel in the treatment 4 wines. Table 1 shows the sensory data of only treatments 1,2 and 3. Interestingly enough, treatments 2 and 3 were associated more with negative characteristics, such as sulphur aroma, and treatment 1 more with the positive, fruity characteristics. Small but significantly differences were thus observed for tropical, fruity and over-aged aromas in treatment 1 , where the wines were stored at $-4^{\circ} \mathrm{C}$, and these often were significantly different from the other two treatments. However, it must be borne in mind that, although significant, these differences were relatively small. It thus seems that the 2009 Sauvignon blanc wines (closed under cork) were more sensitive to the slightly higher temperatures in treatments 2 and 3 than the 2010 Chenin blanc wines (closed under screw top). This could be due to different reasons: the fact that the Sauvignon blanc was one year older than the Chenin blanc and thus more sensitive to temperature increases, or the effect of the closure, since the permeation of oxygen through cork is higher than through screw tops (Silva et al., 2011). However, it seems that South African white wines are more sensitive to higher average temperatures (average of $37^{\circ} \mathrm{C}$ ) than to temperatures variations, as treatments 2 (average of $15.3^{\circ} \mathrm{C}$ ) and 3 (average of $15^{\circ} \mathrm{C}$ ) again did not show significant sensory differences. Elevated storage temperatures have been shown to lead to acid hydrolysis of $3 \mathrm{MHA}$ to $3 \mathrm{MH}$ in Sauvignon blanc wines, which may lead to a loss in the tropical aromas associated with the former

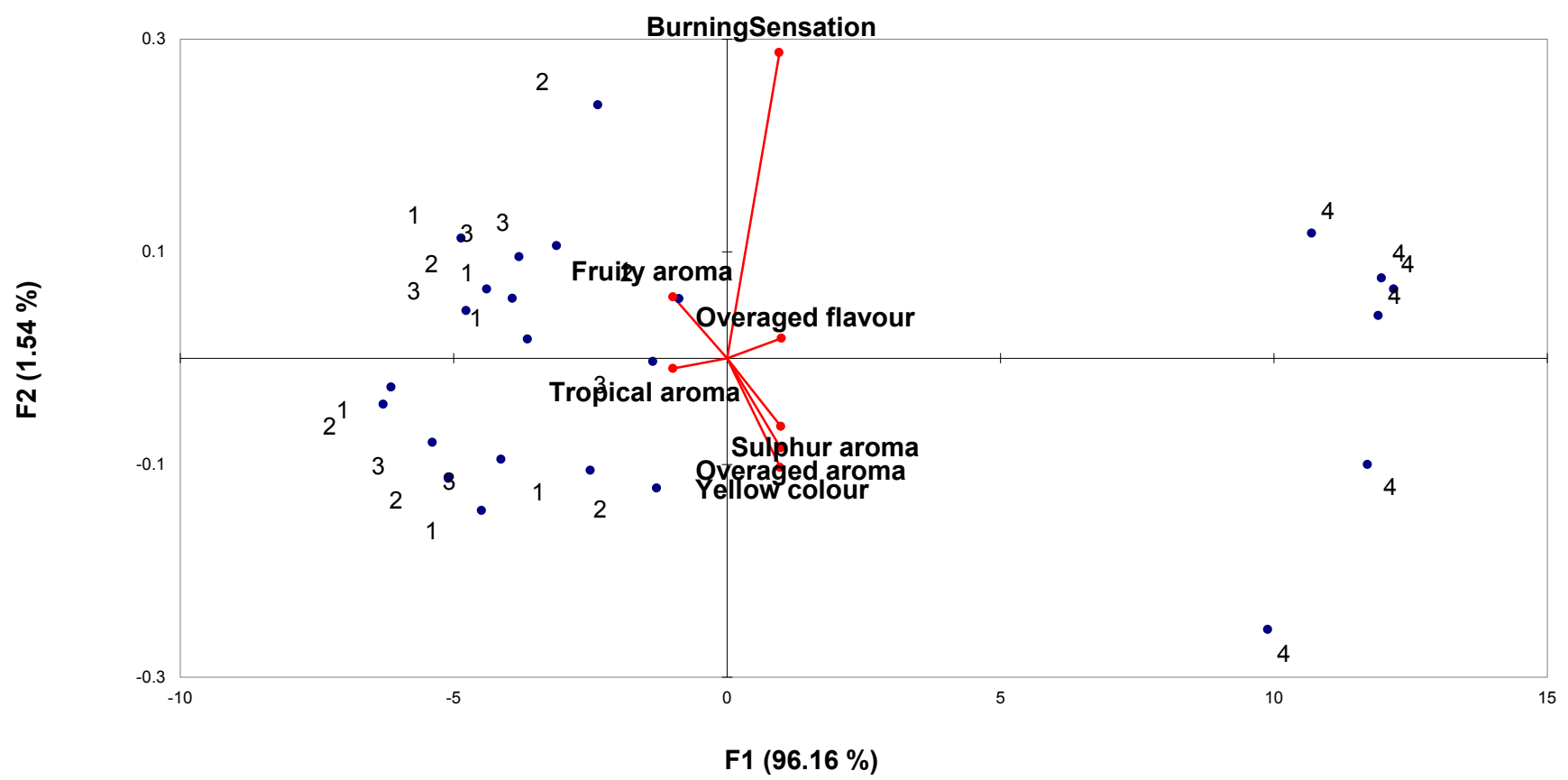

FIGURE

Sensory results of the Chenin blanc wine after the 46-day trial period. The numbers indicate the different treatment's repeats: constant $-4^{\circ} \mathrm{C}$ (treatment 1 ), variable (treatment 2), constant $15^{\circ} \mathrm{C}$ (treatment 3 ) and constant $37^{\circ} \mathrm{C}$ (treatment 4 ). 


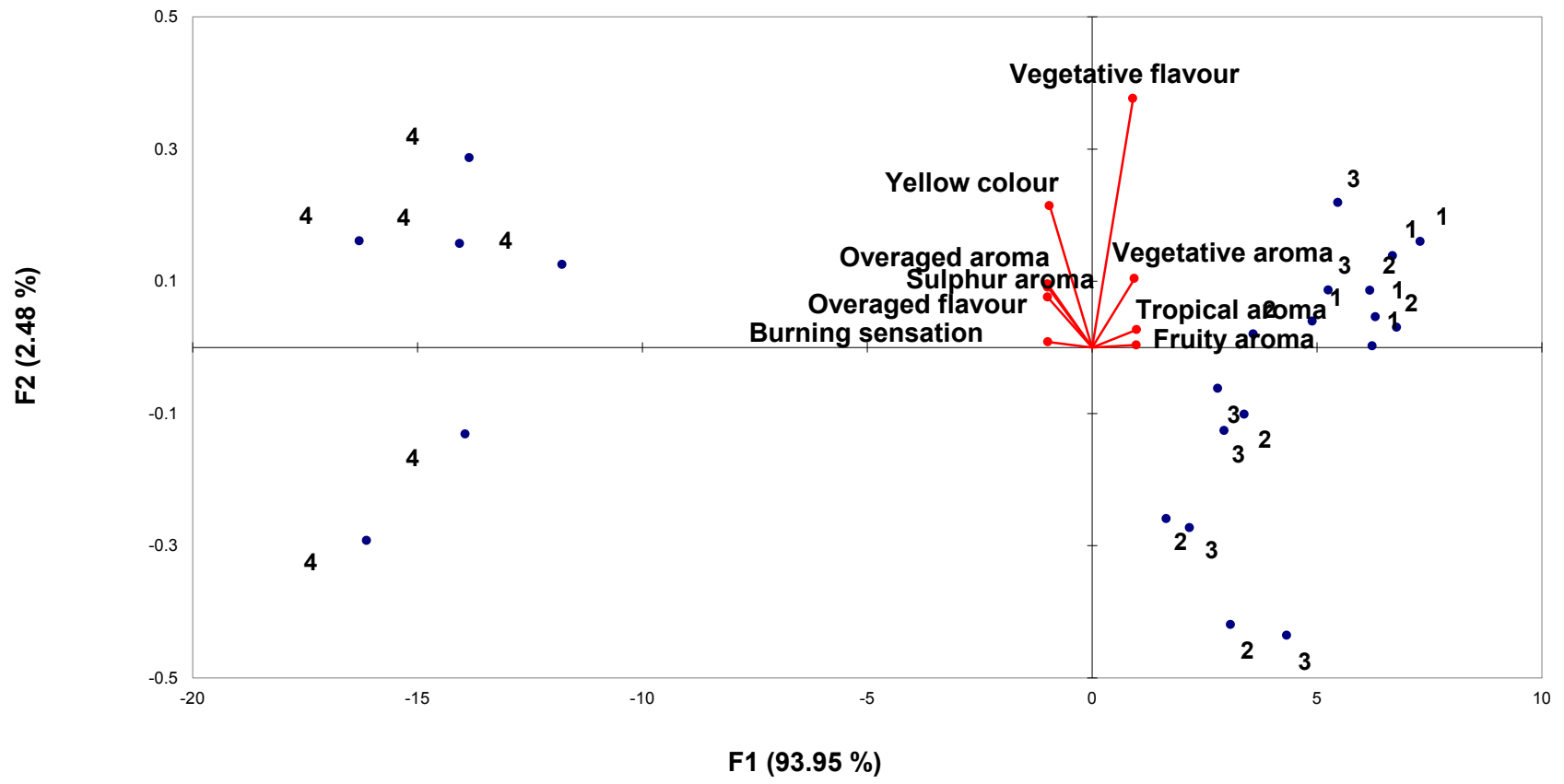

FIGURE 2

Sensory results of the Sauvignon blanc wine after the 46-day trial period. The numbers indicate the different treatment's repeats: constant $-4^{\circ} \mathrm{C}$ (treatment 1 ), variable (treatment 2), constant $15^{\circ} \mathrm{C}$ (treatment 3 ) and constant $37^{\circ} \mathrm{C}$ (treatment 4 ).

TABLE 1

Mean (out of 100) and standard deviation sensory scores for of the Sauvignon blanc wine after the temperature trials for treatments 1, 2 and 3. Constant -4 degree $\mathrm{C}(1)$, variable temperatures (2) and constant 15 degree $\mathrm{C}$ (3).

\begin{tabular}{lccc}
\hline & \multicolumn{1}{c}{ Treatment } & $\mathbf{3}$ \\
\hline Characteristic & $\mathbf{1}$ & $21.4 \pm 2.2^{\mathrm{a}}$ & $21.3 \pm 2.5^{\mathrm{a}}$ \\
Yellow colour & $21.5 \pm 2.9^{\mathrm{a}}$ & $3.1 \pm 5.7^{\mathrm{ab}}$ & $3.3 \pm 7.2^{\mathrm{a}}$ \\
Sulphur aroma & $0.7 \pm 2.1^{\mathrm{b}}$ & $31.1 \pm 7.0^{\mathrm{b}}$ & $31.4 \pm 6.4^{\mathrm{b}}$ \\
Tropical aroma & $34.9 \pm 6.3^{\mathrm{a}}$ & $29.7 \pm 6.9^{\mathrm{b}}$ & $30.1 \pm 8.3^{\mathrm{b}}$ \\
Fruity aroma & $33.7 \pm 6.6^{\mathrm{a}}$ & $2.1 \pm 3.8^{\mathrm{ab}}$ & $3.8 \pm 8.0^{\mathrm{a}}$ \\
Over-aged aroma & $0.2 \pm 1.2^{\mathrm{b}}$ & $26.2 \pm 9.7^{\mathrm{ab}}$ & $25.5 \pm 8.8^{\mathrm{b}}$ \\
Vegetative aroma & $29.3 \pm 8.3^{\mathrm{a}}$ & $5.7 \pm 6.1^{\mathrm{a}}$ & $7.4 \pm 6.7^{\mathrm{a}}$ \\
Burning sensation & $4.9 \pm 6.6^{\mathrm{a}}$ & $20.9 \pm 7.1^{\mathrm{a}}$ & $21.1 \pm 7.5^{\mathrm{a}}$ \\
Vegetative flavour & $23.2 \pm 7.7^{\mathrm{a}}$ & $2.5 \pm 6.1^{\mathrm{a}}$ & $2.6 \pm 7.2^{\mathrm{a}}$ \\
Over-aged flavour & $0.9 \pm 3.1^{\mathrm{a}}$ & & \\
\hline
\end{tabular}

Different letters indicate significance at $\mathrm{p}<0.05$

compound (Coetzee \& Du Toit, 2012; Makhotkina et al., 2012), which could also partially explain decreases in the tropical, fruity aromas even when wines are closed with a screw cap and stored under elevated temperatures.

As the tasting results clearly showed differences between treatment 4 and the other treatments after the 46day trial period, we decided to investigate whether such differences could already be perceived in the Chenin blanc wines exposed to either $15^{\circ} \mathrm{C}$ or $37^{\circ} \mathrm{C}$ at an earlier stage. For significance, 16 out of the 32 responses had to distinguish between the two treatments, (Jackson, 2007). After one week, 11/32 responses distinguished between the two wines, but this increased to $16 / 32$ after two weeks, indicating that the panel could already distinguish between wine from the two treatments at this stage.
Based on the results presented by this investigation, the formation of unwanted aroma compounds in South African white wines during transport by ship are related more to high average temperatures than to temperature fluctuations. Little research has been done on this aspect and it needs to be seen whether similar results are obtained if wines that were produced by different winemaking techniques (oxidative vs reductive handling, different $\mathrm{SO}_{2}$ levels, etc.) are used. This work could assist wine producers in deciding if their wines should be shipped under temperature-controlled conditions if there is prior knowledge of the conditions to which the wines will be exposed during transport. 


\section{LITERATURE CITED}

Biasoto, A.C.T., Catharino, R.R., Sanvido, G.B., Eberlin, M. N. \& Da Silva, M.A.A.P., 2012. Flavour characterization of red wines by descriptive sensory analysis and ESI mass spectrometry. Food Qual. and Pref. 21, 755 762.

Coetzee, C., 2014. Oxidation treatments affecting Sauvignon blanc wine's sensory and chemical composition. Dissertation, Stellenbosch University, Private Bag X1, 7602 Matieland (Stellenbosch), South Africa.

Coetzee, C. \& Du Toit, W.J., 2012. A comprehensive review on Sauvignon blanc aroma with a focus on certain positive volatile thiols. Food Res. Int. 45, 287-298.

Francis, I.L., Sefton, M.A. \& Williams, P.J., 1994. The sensory effects of pre- or post-fermentation thermal processing on Chardonnay and Semillon wines. Am. J. Enol. Vitic. 45, 243-251.

Hopfer, H., Ebeler, S.E. \& Heymann, H., 2012. The combined effects of storage temperature and packaging type on the sensory and chemical properties of Chardonnay. J. Agric. Food Chem. 60, 10743-10754.

Jackson, R.S., 2007. Wine tasting, a professional handbook. Elsevier Academic Press, London.

Lawless, H.T. \& Heymann, H., 2010. Sensory evaluation of food principles and practices. 2nd ed. Springer Science, LLC, New York.

Makkhotkina, O., Pineau. B. \& Kilmartin, P.A., 2012. Effect of storage temperature on the chemical composition and sensory profile of Sauvignon Blanc wines. Aust. J. Grape Wine Res. 18, 91-99.
Marais, J. \& Pool, H.J., 1980. Effect of storage time and temperature on the volatile composition and quality of dry white table wines. Vitis 19, 151-164.

Meyer D., 2002. A study of the impact of shipping/transportation conditions and practices on wine. WineLand, magazine of the SA wine producers. Available: http://www.wynboer.co.za/recentarticles/1202shipping.php3 (Accessed 10 November, 2010)..

Næs, T., Brockhoff, P.B. \& Tomic, O.,2010. Quality control of sensory profile data. In: Statistics For Sensory and Consumer Data. New York, USA, John Wiley \& Sons, Ltd.

Noble, A.C., Arnold, R.A., Buechenstein, J., Leach, E.J., Schmidt, J.O. \& Stern, P.M., 1987. Research Note. Modification of a standardized system of wine aroma terminology. Am. J. Enol. Vitic. 38, 143-148.

Robinson, A.L., Mueller, M., Heymann, H., Ebeler, S.E., Boss, P.K. Solomon, P.S. \& Trengove, R.D., 2010. Effect of simulated shipping conditions on sensory attributes and volatile composition of commercial white and red wines. Am. J. Enol. Vitic. 61, 337-347.

Rodríguez-Bermejo, J., Barreiro, P., Robla, J.I \& Ruiz-García, L., 2007. Thermal study of a transport container. J. Food Eng. 80, 517-527.

Silva, M.A., Julien, M., Jourdes, M. \& Teissedre, P., 2011. Review paper: Impact of closures on wine post-bottling development: a review. Eur. Food Res Technol. 233, 905-914.

Silva Ferreira, A.C., Hogg, T. \& Guedes de Pinho, P., 2003. Identification of key odorants related to the typical aroma of oxidation-spoiled white wines. J. Agric. Food Chem. 51, 1377-1381. 